Supporting Information

Hydrophilic polymer-brush functional fluorescent nanoparticles to suppress nonspecific interactions and enhance quantum yield for targeted cell imaging

Yiting Li ${ }^{1 \#}$, Xiaoping Qian ${ }^{2 \#}$, Xinliu Tan ${ }^{1}$, Xinghua Liu ${ }^{3}$, Yang Li ${ }^{3}$, Dengming Ming ${ }^{1}$, Lihui Zhang ${ }^{\text {* }}$, Yaqiong Yang ${ }^{3 *}$

${ }^{1}$ College of Biological and Pharmaceutical Engineering, Nanjing Tech University, Nanjing 211816, PR China.

${ }^{2}$ College of Polymer Science \& Engineering, College of Chemistry \& Chemical Engineering, Nanjing University, Nanjing 210023, PR China.

${ }^{3}$ College of Pharmacy, Nanjing Tech University, Nanjing 211816, PR China.

${ }^{4}$ College of Food and Pharmaceutical Engineering, Nanjing Normal University, Nanjing 210023, PR China.

Corresponding authors: Yaqiong Yang and Lihui Zhang;

Email: zhanglihui@njnu.edu.cn; Email:yangyq@njtech.eu.cn

\# Yiting Li and Xiaoping Qian contruibuted equally. 


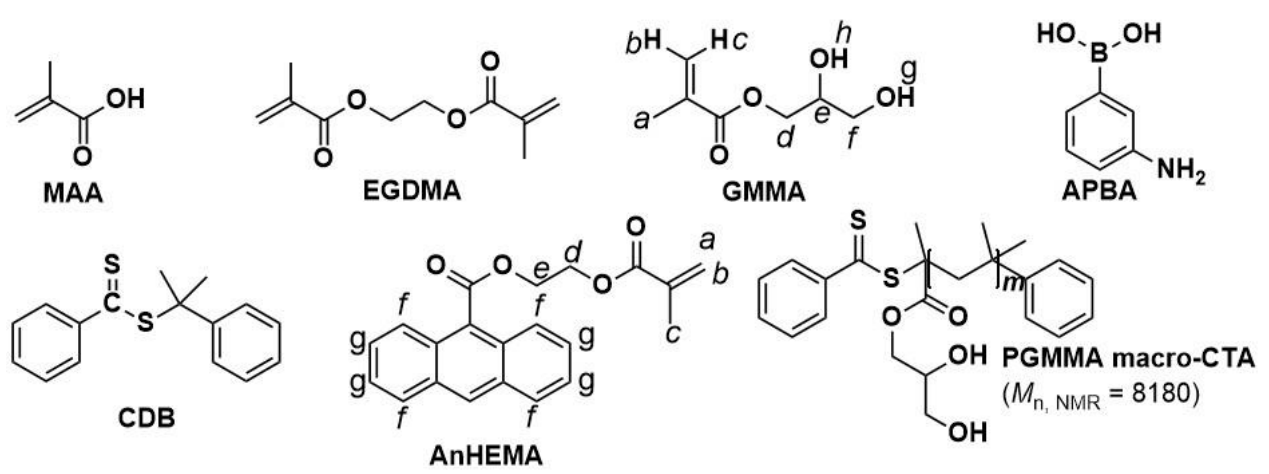

Scheme S1. Chemical structures of some reagents used in the study.

\section{Synthesis and characterization of GMMA}

Glyceryl monomethacrylate (GMMA, Scheme S1) was synthesized by opening the epoxide ring of glycidyl methacrylate with perchloric acid following the previously reported procedure (M. Zhao, C. Zhang, Y. Zhang, X. Guo, H. Yan, H. Zhang, Chem. Commun. 50 (2014) 2208-2210. http://doi.org/10.1039/c3cc49131e.), the detailed procure is as follows: To a beaker, GMA (84.4 mmol) was added, then $48 \mathrm{~mL}$ of $\mathrm{HClO}_{4}(10 \%)$ was added to the above solution drop by drop at $20^{\circ} \mathrm{C}$. This process is detected by a silica gel plate. When the process is finished, $84.0 \mathrm{mmol}$ of $\mathrm{KOH}$ was added to neutralize the unreacted $\mathrm{HClO}_{4}$. Then the precipitation is filtered and the filtrate is purified by petroleum ether for five times, extracted with ethyl acetate for two times. Then removing the ethyl acetate by the rotary evaporator and dried with $\mathrm{MgSO}_{4}$ overnight. At last, the product is purified with $\mathrm{Al}_{2} \mathrm{O}_{3}$ to remove the blocking agent (yield: $72 \%$ ). The ${ }^{1} \mathrm{H}$ NMR $\left(400 \mathrm{MHz}, \mathrm{CDCl}_{3}, \delta\right): 1.89$ (s, 3Ha), 3.56 (q, 2Hf), 3.61 (m, Hg, Hh), 3.92 (m, 1He), 4.14 (d, 1Hd), $5.55(\mathrm{~s}, 1 \mathrm{Hb}), 6.09(\mathrm{~s}, 1 \mathrm{Hc})$.

\section{Synthesis and characterization of well-defined PGMMA with a dithioester end group (PGMMA macro-CTA)}

The synthetic procedure for PGMMA macro-CTA $\left(M_{\mathrm{n}, \mathrm{NMR}}=8180\right)$ is according to previous report (Y. Yang, Z. Wang, H. Niu, H. Zhang, Biosens. Bioelectron. 50 (2016) 580-587. http://dx.doi.org/10.1016/j.bios.2016.07.056), the procedure is as follows: GMMA (13.48 mmol), AIBN $(0.046 \mathrm{mmol}), \mathrm{CDB}(0.081 \mathrm{mmol})$, and methanol $(60 \mathrm{~mL})$ was added into a one-neck round-bottom flask $(100 \mathrm{~mL})$ successively. A clear purple solution was obtained after 5 min of stirring at room temperature. After being purged with argon for $30 \mathrm{~min}$, the reaction mixture was 
sealed and then immersed into a thermostatted oil bath at $60{ }^{\circ} \mathrm{C}$. After being magnetically stirred for $48 \mathrm{~h}$, the reaction solution was precipitated into ethyl ether twice to obtain a light pink polymer, which was dried under vacuum at room temperature for $48 \mathrm{~h}$ to provide the product (yield: $78 \%$ ). The absolute molecular weight of PGMMA macro-CTA was measured by ${ }^{1} \mathrm{H}$ NMR (Varian Unity plus-400 spectrometer, $400 \mathrm{MHz}$ ). Figure. S1 presents the ${ }^{1} \mathrm{H}$ NMR spectrum of PGMMA macro-CTA, from which the number-average molecular weight of the polymer $\left(M_{\mathrm{n}, \mathrm{NMR}}\right)$ was determined to be 8180 by using the following equation:

$$
M_{\mathrm{n}, \mathrm{NMR}}=2 \times\left(S_{\mathrm{d}+\mathrm{c}+\mathrm{e}} / S_{\mathrm{j}}\right) \times M_{\mathrm{GMMA}}+M_{\mathrm{CDB}}
$$

where $S_{\mathrm{d}+\mathrm{c}+\mathrm{e}}$ and $S_{\mathrm{j}}$ refer to the integral of the peaks between 3.327 and $4.341 \mathrm{ppm}$ and that of the peaks between 7 and 8 ppm, $M_{\mathrm{GMMA}}$ is the molar mass of GMMA, and $M_{\mathrm{CDB}}$ is the molar mass of CDB.

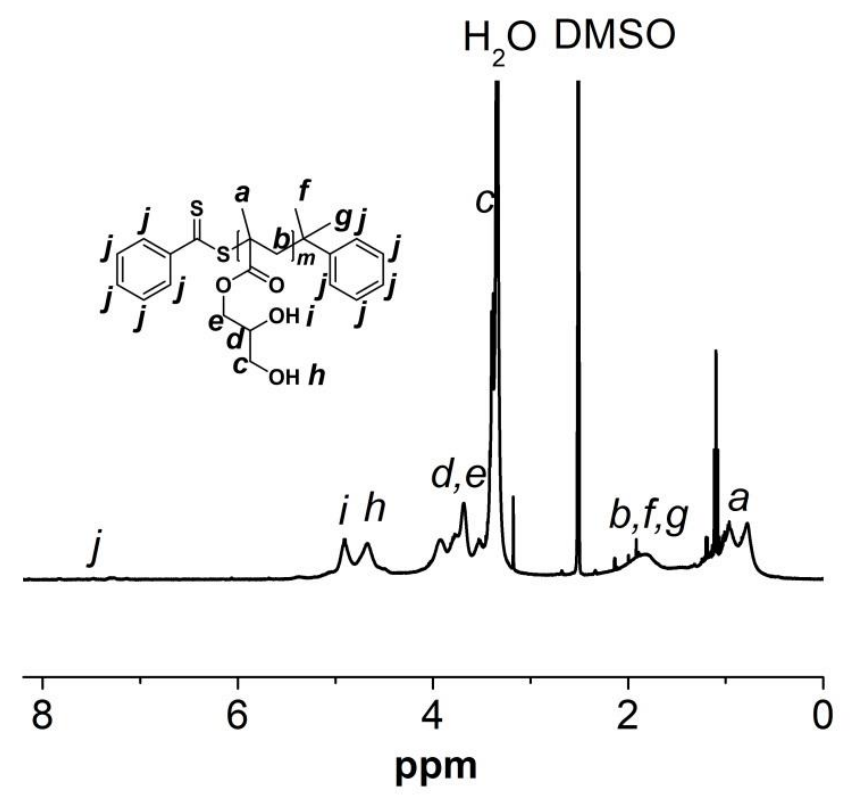

Figure. S1. ${ }^{1} \mathrm{H}$ NMR spectra of PGMMA in DMSO.

Synthesis of the polymerizable fluorescent monomer

\section{(2-hydroxyethylanthrancene-9-carboxylate) methacrylate (AnHEMA)}

Anthracene-9-carboxylic acid (Aladdin, 98\%) (4.864 mmol, $1080.8 \mathrm{~g}$ ), freshly distilled thionyl chloride $(16 \mathrm{~mL})$ were added into a one-neck round-bottom flask $(50 \mathrm{~mL})$. Then the mixture 
firstly stired for $20 \mathrm{~h}$ of stirring at $25^{\circ} \mathrm{C}$. A clear yellow solution was obtained after 90 min of refluxing at $85{ }^{\circ} \mathrm{C}$. The remaining thionyl chloride in reaction mixture was distilled under vacuum. Next, freshly distilled dichloromethane $(20 \mathrm{~mL})$ added to the above solid in order to remove the remaining thionyl chloride. HEMA $(8.90 \mathrm{mmol})$, dried triethylamine $(2040 \mu \mathrm{L})$ and tetrahydrofuran $(16 \mathrm{~mL})$ added to the dropping funnel. The above mixture dropped into the above obtained solid under ice-water bath. After being stirred at $25^{\circ} \mathrm{C}$ for $36 \mathrm{~h}$, the solvent was removed by distillation under vacuum. The resulting solid was then purified with silica gel column chromatography by using dichloromethane/petroleum ether $(\mathrm{v} / \mathrm{v}, 1 / 1)$ as the eluent to provide a yellow product (yield: 65\%). ${ }^{1} \mathrm{H} \mathrm{NMR}\left(400 \mathrm{MHz}, \mathrm{CDCl}_{3}, \mathrm{ppm}\right): 1.99$ (s, $\mathrm{CH}_{3}, 3 \mathrm{Hc}$ ), 4.62 (t, $\left.\mathrm{CH}_{2}, 2 \mathrm{Hd}\right), 4.87$ (t, $\left.\mathrm{CH}_{2}, 2 \mathrm{He}\right), 5.64$ (s, CH, 1Ha), 6.22 (s, CH, 1Hb), 7.50 (m, ArH, 4Hg), 8.01-8.09 (m, ArH, 2Hf), 8.54 (s, ArH, 1Hh).

\section{Characterization of the grafted "living" poly(MAA-co-AnHEMA) fluorescent nanoparticles with $\quad$ surface-bound $\quad$ PBA groups $\quad$ (i.e., grafted-poly(MAA-co-AnHEMA)-PBA)}

Figure S2a presents the UV-vis spectrum of a series of solutions of APBA (with different concentrations of APBA) in the borate buffer $(\mathrm{pH}=7.4)$ solution (determined with a UV-vis spectrophotometer), from which the calibration curve of the APBA solution can be derived (Figure $\mathrm{S} 2 \mathrm{~b})$.
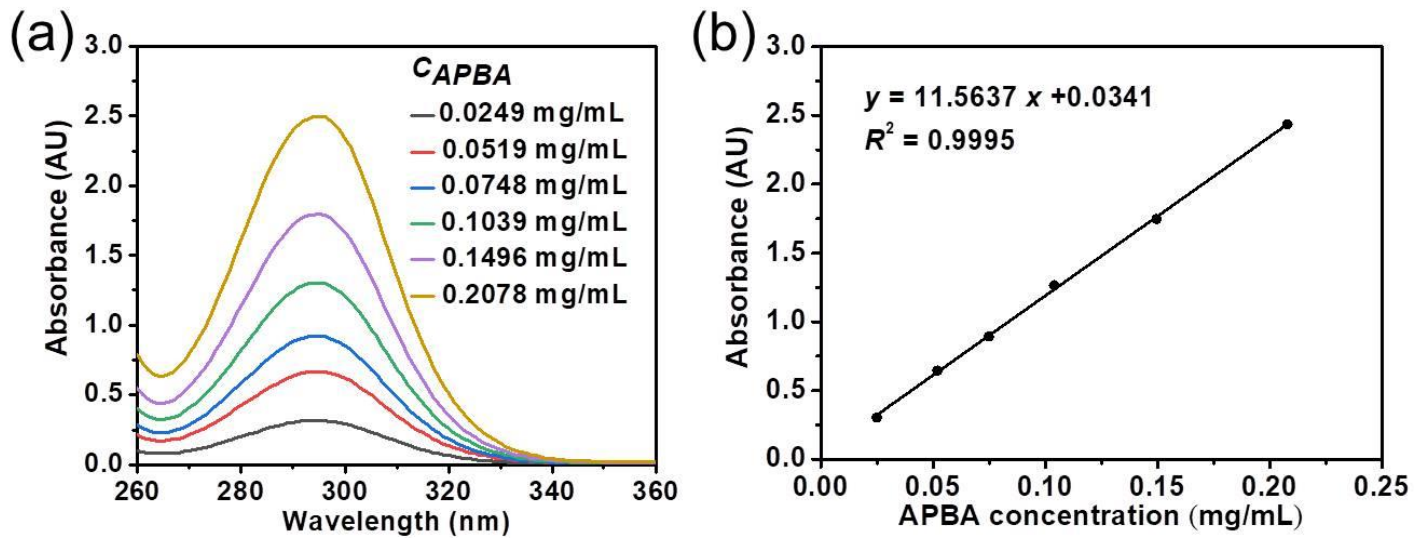

Figure S2. UV-vis spectra of a series of solutions of APBA (with different concentrations $C_{\mathrm{APBA}}$ ) in the PBS buffer ( $\mathrm{pH}=7.4$ ) (a) and the calibration curve obtained by plotting the UV-vis absorbance of the solutions at $294 \mathrm{~nm}$ versus the APBA concentrations (b). 